\title{
BACKGROUND MEASUREMENTS WITH DIFFERENT SHIELDING AND ANTICOINCIDENCE SYSTEMS
}

\author{
H H LOOSLI*, MARKUS FORSTER**, and R L OTLET $†$
}

ABSTRACT. Extremely low background count rates are a necessary condition for both the measurement of ${ }^{39} \mathrm{Ar}$ concentrations in ground and ocean water and of ${ }^{14} \mathrm{C}$ activities in small samples using gas proportional counting techniques. A systematic comparison of the performance of three different designs of shielding systems in four different installations has been made.

Background values of selected gas proportional counters were measured, compared and separated into their various components. Acceptably low backgrounds were obtained in all the systems tried. The performance of a $\mathrm{NaI}$ shield in a surface laboratory was found to be at least equal to the best obtained with a gas anticoincidence detector in a deep underground laboratory.

\section{INTRODUCTION}

Only a few institutions are fortunate enough to possess a deep underground laboratory in which to operate their low-level counting systems. The improvement in background which such locations bring enables the detection and measurement of the very lowest specific activities, which is sometimes essential for the application of certain isotope techniques in the environmental sciences. One example is the application of ${ }^{39} \mathrm{Ar}$ in isotope measurements in hydrology and oceanography where $0.1 \mathrm{cpm}$ background is obtained for a $100 \mathrm{cc}$ counter filled to $19 \mathrm{bar}$ with P-5 counting gas (containing argon extracted from ground water) and as low as $0.2 \mathrm{cpm}$ is obtained for $16 \mathrm{cc}$ counters filled to $30 \mathrm{bar}$ pressure P-8 from ocean water (Loosli, Heiman \& Oeschger, 1980). (The corresponding net standard count rates of recent samples with tropospheric ${ }^{39} \mathrm{Ar}$ concentrations are $0.18 \mathrm{cpm}$ and $0.038 \mathrm{cpm}$, respectively.) Since it has now been demonstrated that ${ }^{39} \mathrm{Ar}$ results are consistent with other methods (Loosli, 1983; Andrews et al, 1984; Forster, Moser \& Loosli, 1984; Schlitzer et al, 1985) interest in measuring ${ }^{39} \mathrm{Ar}$, especially for groundwater dating, has expanded. To facilitate this expansion, the question arose whether similar background values could also be obtained in near-surface or even surface laboratories through the application of sophisticated active and passive shielding systems. The question is also relevant to those institutions which use gas-proportional counting techniques for the measurement of ${ }^{14} \mathrm{C}$ activities in very small samples. Such measurements using miniature counters have been successfully operated routinely since 1979 (Sayre $e t a l, 1981$ ) and a review of the development of the techniques appears in this issue (Otlet, Huxtable \& Sanderson, 1986).

The procedure for the intercomparative tests involved the selection of a number of different but known low-background counters, the details of which are listed in Table 1. Each counter was given a fresh filling of background gas at its originating laboratory, tested for background with that filling, and then carefully transported to the other laboratories for the comparative measurements. No deterioration of the counting gas quality, eg, FRG

\footnotetext{
* Physics Institute, University of Bern, Sidlerstrasse 5, CH-3012 Bern, Switzerland

** GSF-Institute for Radiohydrometry, Ingolstadter Landstrasse 1, 8042 Neuherberg,
}

† Isotope Measurements Laboratory, AERE Harwell, Oxfordshire OX11 ORA, UK 
TABLE 1

Proportional counters used for comparison of background values measured in different laboratories

\begin{tabular}{ccccrr}
\hline $\begin{array}{c}\text { Active } \\
\text { volume } \\
(\mathbf{c c})\end{array}$ & $\begin{array}{c}\text { Length/ } \\
\text { diameter } \\
(\mathrm{cm})\end{array}$ & $\begin{array}{c}\text { Counter } \\
\text { geometry }\end{array}$ & Material & gas & \multicolumn{2}{c}{ Filling } \\
\hline 4.7 & $5.0 / 1.1$ & Cylinder & $\mathrm{Cu}$ & $\mathrm{P}-10$ & 5.4 \\
16 & $12 / 1.3$ & Cylinder & $\mathrm{Cu}$ & $\mathrm{P}-8$ & 4.7 \\
30 & $12 / 1.8$ & Cylinder & Quartz/iron & $\mathrm{CO}$ & 3.9 \\
100 & $21 / 2.5$ & Cylinder & $\mathrm{Cu}$ & $\mathrm{P}-5$ & 19 \\
113 & $-/ 6$ & Sphere & $\mathrm{Cu}$ & $\mathrm{P}-10$ & 5 \\
\hline
\end{tabular}

due to electronegative impurity build-up, was evident over the full period of the tests. Tests on the counters were thus carried out with four different shielding-system installations:

1) a deep underground laboratory which employs a gas counter as the anticoincidence guard shield detector,

2) a near-surface laboratory using a similar anticoincidence system,

3) a near-surface laboratory using a plastic-scintillator anticoincidence system, and,

4) a surface laboratory using a large $\mathrm{NaI}$ crystal as the anticoincidence detector. tions.

It was not, however, possible to measure all counters in all installa-

Details of the locations of the four laboratories and the shielding systems employed for the intercomparative background tests are given in Table 2 and schematically in Figure 1.

\section{RESULTS AND DISCUSSION}

Results of the intercomparative measurements are given in Table 3. 'Total count-rate' refers to the count rate of the counters tested obtained with no anticoincidence subtraction, $i e$, with the relevant active guard counter switched off but with the counter located within its normal position within the shield. Correspondingly, 'Background' refers to the residual count-rate in the same position but with the active shield in operation and all coincident pulses subtracted.

In collating a consistent set of values from all the counters at the different locations, it was clearly essential to ensure that identical pulse spectrum regions were being considered for each result. This was achieved by making the overall gain and lower threshold positions comparable in all cases using an external gamma-ray source (usually ${ }^{241} \mathrm{Am}$ ) to excite the appropriate $\mathrm{K}$-alpha $\mathrm{x}$-ray line ( $\mathrm{Cu}$ or $\mathrm{Fe}$ as the case may be) which then marked a common calibration point in the various spectra. Sensitive positioning of the x-ray peak to a given channel number was achieved by means of high voltage adjustments.

Also included in Table 3 is a list of the 'estimated self-activity of the counter material', calculated from a breakdown of the individual components which contribute to the total observed background. For this, the pro- 
TABLE 2

Active and passive shieldings used in different low-level laboratories for reduction of counter background

\begin{tabular}{|c|c|c|c|c|}
\hline & $\begin{array}{c}\text { Bern } \\
\text { deep- } \\
\text { underground }\end{array}$ & $\begin{array}{c}\text { Bern } \\
\text { near-surface }\end{array}$ & $\begin{array}{l}\text { Neuherberg } \\
\text { near-surface }\end{array}$ & Harwell surface \\
\hline \multirow[t]{4}{*}{$\begin{array}{l}\text { Passive } \\
\text { shield }\end{array}$} & $\begin{array}{l}70 \mathrm{~m}^{*} \text { sand- } \\
\text { stone }\end{array}$ & $5 \mathrm{~m} *$ (building) & $3 \mathrm{~m} *$ (building) & $0.1 \mathrm{~m} *$ (building) \\
\hline & $\begin{array}{l}40 \mathrm{~cm} \text { special } \\
\text { low level } \\
\text { concrete }\end{array}$ & & $10 \mathrm{~cm} \mathrm{~Pb}$ & $\begin{array}{l}20.4 \mathrm{~cm} \text { old } \mathrm{Fe} \\
15 \mathrm{~cm} \text { paraffin wax }\end{array}$ \\
\hline & $10 \mathrm{~cm}$ old $\mathrm{Pb}$ & $10 \mathrm{~cm}$ old $\mathrm{Pb}$ & $\begin{array}{l}0.5 \mathrm{~cm} \text { old } \mathrm{Fe} \\
\text { (housing of } \\
\text { plastic scin- } \\
\text { tillator) }\end{array}$ & $\begin{array}{l}2.6 \mathrm{~cm} \text { old Fe inside } \\
\text { layer }\end{array}$ \\
\hline & $\begin{array}{l}2 \mathrm{~cm} \text { old } \mathrm{Pb} \\
\text { tube between } \\
\text { guard and } \\
\text { main coun- } \\
\text { ter }\end{array}$ & $\begin{array}{l}2 \mathrm{~cm} \text { old } \mathrm{Pb} \\
\text { tube between } \\
\text { guard and } \\
\text { main coun- } \\
\text { ter }\end{array}$ & $\begin{array}{l}2 \mathrm{~cm} \text { old } \mathrm{Pb} \\
\text { inside scintilla- } \\
\quad \text { tor well }\end{array}$ & $\begin{array}{l}0.5 \mathrm{~mm} \mathrm{Cu} \text { in well of } \\
\mathrm{NaI}\end{array}$ \\
\hline $\begin{array}{l}\text { Active } \\
\quad \text { shield }\end{array}$ & \multicolumn{2}{|c|}{$\begin{array}{l}\text { Gas proportional tube as guard } \\
\text { counter. High efficiency for } \\
\text { detection of muons, small for } \\
\text { detection of } \gamma \text { radiation }\end{array}$} & $\begin{array}{l}\text { Large plastic } \\
\text { scintillator, } \\
20 \mathrm{~cm} \text { thick } \\
\text { at minimum } \\
\text { with hole for } \\
\text { proportional } \\
\text { counter. } \\
\text { High effi- } \\
\text { ciency for } \\
\text { muon detec- } \\
\text { tion, me- } \\
\text { dium for de- } \\
\text { tection of } \gamma \\
\text { radiation }\end{array}$ & $\begin{array}{l}\text { Large NaI crystal, } \\
\text { outer diameter } \\
30 \mathrm{~cm} \text {, inner di- } \\
\text { ameter } 9 \mathrm{~cm}, \\
\text { length } 30 \mathrm{~cm}, 2 \times \\
3 \text { photomulti- } \\
\text { pliers. High effi- } \\
\text { ciency for detec- } \\
\text { tion of muons } \\
\text { and } \gamma \text { radiation }\end{array}$ \\
\hline
\end{tabular}

*Iepth given in meter water equivalent

cedures previously developed and the parameters determined from the two locations in Bern (ie, the deep underground and near-surface laboratories) were used (Loosli, Heimann \& Oeschger, 1980; Oeschger et al, 1981). The pressure dependence relationships of background values for the proportional counters were also taken from that work as was the general conclusion that the contributions from gamma rays and self-activity (alpha and beta) are the only components which need be considered here. Using these estimates, the pressure independent values of the self-activity of the counter materials and associated contaminants were deduced. Values from $7 \times$ $10^{-5}$ to $1.5 \times 10^{-3} \mathrm{cpm}$ per $\mathrm{cm}^{2}$ of counter surface were obtained. This large variation in self-activity of the counter tubing is highly undesirable and it confirms previous experience that several samples of material have usually to be tested before a material of really low-level quality is found. Unfortunately, pre-construction surface activity measurements are only capable of detecting rather high concentrations of radioactive contaminants and, although very low values are possible, in the past it has only been possible to make an assessment of material suitability after the counter has been constructed! 


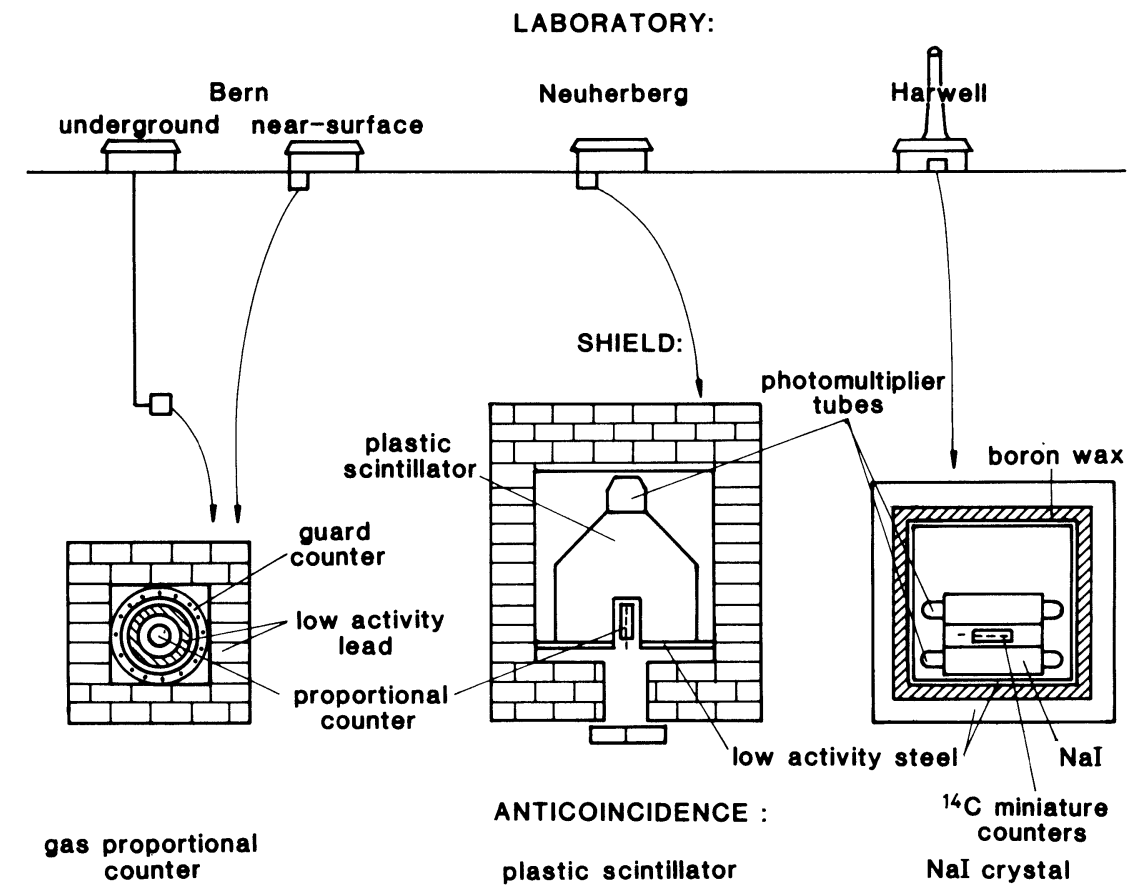

Fig 1. Schematic of the low-level measuring laboratories at Bern, Neuherberg, and Harwell, highlighting the principal differences in depth underground, passive shield designs, and anticoincidence guard-counter systems employed.

Having obtained the self-activity values the next step was to calculate the contribution of external gamma rays to the residual backgrounds. This parameter is of most value in comparing the effectiveness of different shields. To obtain it, the following three components were subtracted from the overall background result, again using the parameters (and procedures) established at Bern and reported earlier in Loosli, Heimann \& Oeschger (1980):

1) self-activity: as described above, 2) muon count rate: that fraction which is not cancelled by the gas anticoincidence counters, and 3) a volume and pressure dependent gamma-ray contribution: which varies with different filling pressures but is only really important at high pressures.

The residual background is a gamma-ray contribution, described below, and corresponds to the value obtained from an extrapolation of the counter pressure to a hypothetical zero pressure filling, $(i e, \mathrm{p}=0)$ and approximates to that calculated from the $\mathrm{S} \gamma \cdot \overline{\mathrm{OR}} / 4$ expression given in the above reference (Loosli, Heimann \& Oeschger, 1980). This gamma-ray contribution describes a component expected to be proportional to the inner surface area of the counter and originating from the fraction of the external gamma rays which interact with the innermost surface of the counter wall at a depth from which emitted electrons have sufficient energy still to escape the surface and reach the active counter volume. The residual 
TABLE 3

Total and background count rates of proportional counters in different laboratories. Description of counters and their filling pressures (see Table 1)

\begin{tabular}{|c|c|c|c|c|}
\hline $\begin{array}{l}\text { Proportional } \\
\text { counter }\end{array}$ & $\begin{array}{l}\text { Bern deep- } \\
\text { underground }\end{array}$ & $\begin{array}{c}\text { Bern } \\
\text { near-surface }\end{array}$ & $\begin{array}{l}\text { Neuherberg } \\
\text { near-surface }\end{array}$ & $\begin{array}{l}\text { Harwell } \\
\text { surface }\end{array}$ \\
\hline \multicolumn{5}{|c|}{ Total count rate (cpm) } \\
\hline $4.7 \mathrm{cc}$ & 0.26 & 2.9 & 2.4 & 3.8 \\
\hline $16 c c$ & 0.8 & 10.3 & - & 11.7 \\
\hline $30 \mathrm{cc}$ & 1.35 & - & - & - \\
\hline $100 \mathrm{cc}$ & 3.2 & 35 & - & - \\
\hline $113 \mathrm{cc}$ & 2.2 & 22.5 & $24(23 *)$ & - \\
\hline \multicolumn{5}{|c|}{ Background (cpm) } \\
\hline \multirow[t]{2}{*}{$4.7 \mathrm{cc}$} & 0.0083 & 0.036 & 0.038 & 0.0078 \\
\hline & \pm 0.0010 & \pm 0.002 & \pm 0.003 & \pm 0.0014 \\
\hline \multirow{2}{*}{$16 \mathrm{cc}$} & 0.028 & 0.13 & - & 0.026 \\
\hline & \pm 0.002 & - & - & \pm 0.002 \\
\hline \multirow[t]{2}{*}{$30 \mathrm{cc}$} & 0.041 & - & - & 0.040 \\
\hline & \pm 0.0025 & - & - & \pm 0.002 \\
\hline $100 \mathrm{cc}$ & 0.115 & 0.43 & - & - \\
\hline \multirow[t]{2}{*}{$113 \mathrm{cc}$} & 0.207 & 0.40 & 0.42 & - \\
\hline & \pm 0.012 & \pm 0.02 & $(0.30 *)$ & - \\
\hline \\
\hline \multicolumn{5}{|c|}{$\begin{array}{l}\text { Estimated self activity of counter material }\left(\mathrm{cpm} / \mathrm{cm}^{2}\right) \\
4.7 \mathrm{cc} \\
1.9 \times 10^{-4}\end{array}$} \\
\hline $16 c c$ & \multicolumn{4}{|c|}{$\begin{array}{c}3.6 \times 10^{-4} \text { (lowest value obtained for several } \\
\text { counters: } 7 \times 10^{-5} \text { ) }\end{array}$} \\
\hline $30 \mathrm{cc}$ & \multicolumn{4}{|c|}{$3.1 \times 10^{-4}$} \\
\hline $100 \mathrm{cc}$ & \multicolumn{4}{|l|}{$2.9 \times 10^{-4}$} \\
\hline $113 \mathrm{cc}$ & \multicolumn{4}{|l|}{$1.5 \times 10^{-3}$} \\
\hline
\end{tabular}

*With additional $2 \mathrm{~cm} \mathrm{~Pb}$ inside the scintillator well

background component is plotted as a function of the inner counter surface area in Figure 2. The linear relations observed for the values measured in Neuherberg, Harwell, Bern deep-underground and (but with greater scatter) in the Bern near-surface laboratories, demonstrate that this model of splitting the background into the stated components, and the values of the parameters used, yield a consistent picture. This is a significant result in view of the different sizes of counters used ( 4.7 to $110 \mathrm{cc}$ ), the different geometries of the counters (cylinders and sphere), and the different shields involved. It is stressed, however, that the apparent agreement is necessarily limited by the precision of the measurements, which in some cases were determined from relatively short total counting times in comparison with the extremely low count rates involved.

A further feature illustrated in Figure 2 is the relative efficiency with which the different shields attenuate the gamma-ray component, the steeper lines indicating less efficient removal from the overall background.

Table 4 summarizes the efficiencies of the shields in removing the main components of the total gamma ray flux, $i e$, external gamma rays attenuated by the passive shield and muon-induced gamma rays generated within the passive shield. The data was deduced from direct comparative measurements of the gamma-ray fluxes inside and outside the shields together with some absorption estimates as shown. The values indicate that external gamma rays are essentially eliminated by all the passive shields considered 


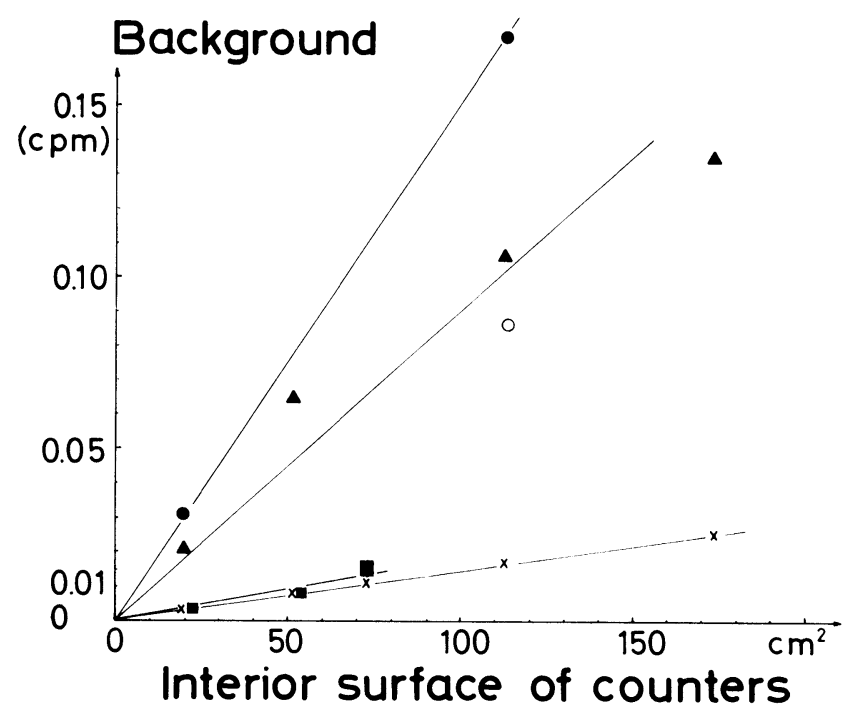

Fig 2. $\gamma$-ray contribution to background as a function of the inner surface area of the counters (derivation as explained in the text). The observed linear correlation confirms the assumption that this component is due only to the effects of external $\gamma$ radiation at the counter surface. The flux of $\gamma$ radiation is low in the Bern underground laboratory $(\mathrm{x})$ and in the NaI shield at Harwell $(\boldsymbol{\square})$. It is higher in the Bern cellar laboratory $(\boldsymbol{\Delta})$ and in the plastic scintillation shield in Neuherberg $(\bullet)$. A lower value has been obtained at Neuherberg $(0)$ with the use of an additional $2 \mathrm{~cm} \mathrm{~Pb}$ shield within the well.

TABLE 4

Measured and estimated $\gamma$ reductions by active and passive shields

\begin{tabular}{|c|c|c|}
\hline Laboratory & $\begin{array}{l}\text { Elimination of external } \\
\gamma \text { flux }\end{array}$ & $\begin{array}{l}\text { Elimination of } \mu \text {-induced } \gamma \\
\text { flux regenerated in passive } \\
\text { shield }\end{array}$ \\
\hline $\begin{array}{l}\text { Bern deep- } \\
\text { under- } \\
\text { ground }\end{array}$ & $\begin{array}{l}40 \mathrm{~cm} \text { low activity con- } \\
\text { crete and } 10 \mathrm{~cm} \mathrm{~Pb} \\
\text { shield: factor }>100\end{array}$ & $\begin{array}{l}\text { Reduction of } \mu \text { flux (by go- } \\
\text { ing underground): factor } \\
11 \\
2 \mathrm{~cm} \text { Pb between guard and } \\
\text { main counter: } \\
\text { factor } \simeq 3\end{array}$ \\
\hline $\begin{array}{l}\text { Bern near-sur- } \\
\text { face }\end{array}$ & $\begin{array}{l}\text { 10cm } \mathrm{Pb} \text { shield: factor }> \\
100\end{array}$ & $\begin{array}{l}2 \mathrm{~cm} \mathrm{~Pb} \text { between guard and } \\
\text { main counter: factor } 3\end{array}$ \\
\hline $\begin{array}{l}\text { Neuherberg } \\
\text { near-surface }\end{array}$ & $\begin{array}{l}10 \mathrm{~cm} \mathrm{~Pb} \text { shield: factor }> \\
100 \\
\text { Scintillator as absorber } \\
\text { and as active anticoin- } \\
\text { cidence for Compton } \\
\gamma \mathrm{s}: \text { factor } \simeq 10\end{array}$ & $\begin{array}{l}\text { Scintillator as absorber and } \\
\text { as active anticoincidence } \\
\text { for Compton } \gamma \mathrm{s}: \text { factor } 10 \\
(2 \mathrm{~cm} \mathrm{~Pb} \text { in sc well: factor } \simeq \\
3)\end{array}$ \\
\hline $\begin{array}{l}\text { Harwell sur- } \\
\text { face }\end{array}$ & $\begin{array}{l}23 \mathrm{~cm} \mathrm{Fe:} \mathrm{factor}>100 \\
\text { NaI as absorber and as } \\
\text { active anticoincidence } \\
\text { for Compton } \gamma \mathrm{s}: \text { fac- } \\
\text { tor } \simeq 20 \text { (estimated)* }\end{array}$ & $\begin{array}{l}\text { NaI as absorber and as active } \\
\text { anticoincidence for } \\
\text { Compton } \gamma \text { s: factor } \simeq 20 \\
\text { (estimated)* }\end{array}$ \\
\hline
\end{tabular}

*Factor 15 measured for direct absorption of ${ }^{137} \mathrm{Cs} \gamma$ rays 
but the muon-induced gamma rays are not removed so effectively in some cases. These muon-induced gamma rays, together with any possible selfactivity of the shielding materials, account for the main fraction of the residual in the backgrounds observed. In this respect, the worst situation is thus seen in the results from the near-surface laboratory at Bern and Neuherberg (without inner shield), where the attenuation of the muon-induced gamma rays in the shield is least, but the best is probably the deep underground laboratory at Bern where, although the shield is no different, the muon flux itself is greatly reduced at that depth in passage through the ground. Neuherberg and Harwell reduce the muon-induced gamma-ray component in their massive active shield counters both through passive absorption and more importantly by active detection of the Compton gamma rays in the anticoincidence counter itself. In this respect, the NaI crystal detector at Harwell has by far the best gamma-ray detection efficiency and this is demonstrated by the very low backgrounds achieved even at the surface location.

\section{CONCLUSIONS}

In real terms extremely low background values were achieved in all laboratory locations and shields tested. Although the deep underground laboratory has the advantage of a lower muon flux and hence a lower muoninduced gamma-ray component in the residual background, the use of a gamma-ray sensitive active anticoincidence shield can overcome this especially by the use of the NaI crystal detector. Acceptable results can be obtained, however, with the lower efficiency plastic scintillator shield backed up with an additional, radioactively pure, lead inner lining of a few centimeters' thickness.

Analysis of the test data into individual contributions suggests that of most importance is the cancellation of gamma rays induced by muons in the passive shield and also the avoidance of radioactive impurities (self-activity) in all the constructional materials in the vicinity of the sample counters.

From these measurements and estimates it seems completely feasible to use small counters for ${ }^{39} \mathrm{Ar}$ measurements in many surface laboratories, eg, ${ }^{39} \mathrm{Ar}$ applications for groundwater dating look possible in shields employing active plastic-scintillator anticoincidence systems whereas applications even for small volume ocean water samples in miniature, high pressure, counters, could be performed in a NaI well crystal system.

It is of considerable interest to consider whether the introduction of a $\mathrm{NaI}$ crystal as an active anticoincidence shield could produce significantly lower backgrounds and hence improve the precision of the measurements in the deep underground laboratory in Bern. The estimates in this paper show that for those small counters which have the lowest self-activity up to $70 \%$ of the background actually obtained is due to residual gamma radiation. A necessary requirement of a NaI crystal that would achieve this elimination would clearly be that it should itself be manufactured of radioactively clean materials. Since the requirements for the levels of these activities are extremely low and because variations of self-activity in two dif- 
ferent crystals have been observed in Harwell, success is not easy to achieve and, unfortunately, cannot be guaranteed. An attempt however seems worthwhile, because this could also reduce the long counting times which are at present necessary.

\section{ACKNOWLEDGMENTS}

Thanks are due Heribert Moser and Hans Oeschger for their continuous support throughout these investigations and to Ferdinand Buheitel, Jill Walker, Sue Dadson, and Peter Kalt for their help in carrying out the measurements. The financial assistance of 'Deutsche Forschungsgemeinschaft' and 'Schweizer Nationalfonds' is gratefully acknowledged.

\section{REFERENCES}

Andrews, J W, Balderer, W, Bath, A H, Clausen, H B, Evans, G V, Florkowski, T, Goldbrunner, J E, Ivanovich, M, Loosli, $\mathrm{H} \mathrm{H}$ and Zojer, H, 1984, Environmental isotope studies in two aquifer systems: A comparison of groundwater dating methods, in Isotope hydrology, Proc: Vienna, IAEA, p 535-576.

Forster, M, Moser, H and Loosli, H H, 1984, Isotope hydrological study with Carbon-14 and Argon-39 in the Bunter sandstones of the Saar region, in Isotope hydrology, Proc: Vienna, IAEA, p 515-533.

Loosli, H H, 1983, A dating method with ${ }^{39}$ Ar: Earth Planetary Sci Letters, v 63, p 51-62.

Loosli, H H, Heimann, M and Oeschger, H, 1980, Low level gas proportional counting in an underground laboratory, in Stuiver, $\mathrm{M}$ and $\mathrm{Kra}, \mathrm{R} \mathrm{S}$, eds, Internatl ${ }^{14} \mathrm{C}$ conf, 10 th, Proc: Radiocarbon, v 22, no. 2, p 461-470.

Oeschger, H, Beer, J, Loosli, H H and Schotterer, U, 1981, Low level counting systems in deep underground laboratories, in Methods of low-level counting and spectrometry, Proc: Vienna, IAEA, p 459-474.

Otlet, R L, Huxtable, G and Sanderson, D C W, 1986, The development of practical systems for ${ }^{14} \mathrm{C}$ measurement in small samples using miniature counters, in Stuiver, $\mathrm{M}$ and $\mathrm{Kra}$, R S, eds, Internatt ${ }^{14} \mathrm{C}$ conf, 12th, Proc: Radiocarbon, this issue.

Sayre, E V, Harbottle, G, Stoenner, R W, Otlet, R L and Evans, G V, 1981, Small gas proportional counters for the ${ }^{14} \mathrm{C}$ measurement of very small samples, in Methods of low-level counting and spectrometry, Proc: Vienna, IAEA, p 393-407.

Schlitzer, R, Roether, W, Weidemann, U, Kalt, P and Loosli, H, 1985, A meridional ${ }^{14} \mathrm{C}$ and ${ }^{39}$ Ar section in the North East Atlantic deep water: Jour Geophys Research, v 90, no. C 4, p 6945-6952. 